Published in final edited form as:

Semin Oncol Nurs. 2012 February ; 28(1): 29-44. doi:10.1016/j.soncn.2011.11.004.

\title{
Natural Products for Cancer Prevention
}

\author{
Heather Greenlee, ND, $\mathrm{PhD}^{1,2,3}$ \\ ${ }^{1}$ Department of Epidemiology, Mailman School of Public Health, Columbia University, New York, \\ NY \\ 2Department of Medicine, College of Physicians and Surgeons, Columbia University, New York, \\ NY \\ ${ }^{3}$ Herbert Irving Comprehensive Cancer Center, Columbia University, New York, NY
}

\begin{abstract}
OBJECTIVES-To review the clinical trial literature on the use and effects of natural products for cancer prevention.

DATA SOURCES-Clinical trials published in PubMed.

CONCLUSION-There is a growing body of literature on the use of natural products for cancer prevention. To date, few trials have demonstrated conclusive benefit. Current guidelines recommend against the use of natural products for cancer prevention.
\end{abstract}

IMPLICATIONS FOR NURSING PRACTICE-Clinicians should ask patients about their use of natural products and motivations for use. If patients are using natural products specifically for cancer prevention, they should be counseled on the current guidelines, as well as their options for other cancer prevention strategies.

\section{Keywords}

cancer; cancer prevention; multivitamins; vitamins; botanicals; medicinal mushrooms; probiotics; natural products; clinical trials; review

\begin{abstract}
Individuals born in the US today have a $41 \%$ lifetime risk of being diagnosed with cancer, a sobering statistic that has urged the health care community to identify effective methods of cancer prevention. ${ }^{1}$ Primary cancer prevention aims to reduce the risk of an individual developing cancer through the use of chemopreventive agents, the avoidance of exposure to environmental carcinogens, and the surgical removal of susceptible organs. ${ }^{2}$ Secondary cancer prevention relies on early detection and screening measures to identify precancerous and/or early stage tumors which are often more responsive to treatment than later stage tumors. Tertiary cancer prevention, often referred to as cancer control, aims to reduce the risk of recurrence, reduce the risk of metastasis, prevent second primary cancers, and prevent other cancer-related complications. This article focuses on the use of natural products for primary cancer prevention. The article reviews the clinical trial evidence on the
\end{abstract}

\footnotetext{
(C) 2011 Elsevier Inc. All rights reserved.

Corresponding Author: Heather Greenlee, ND, PhD, Columbia University, 722 West $168^{\text {th }}$ Street, Room 733, New York, NY 10032, Telephone: 212/342-4130; Fax: 212/305-9413; hg2120@ columbia.edu.

Publisher's Disclaimer: This is a PDF file of an unedited manuscript that has been accepted for publication. As a service to our customers we are providing this early version of the manuscript. The manuscript will undergo copyediting, typesetting, and review of the resulting proof before it is published in its final citable form. Please note that during the production process errors may be discovered which could affect the content, and all legal disclaimers that apply to the journal pertain.
} 
effectiveness of natural products for cancer prevention, including vitamins and minerals, botanicals, probiotics, and other agents of interest. The use of natural products has increased in the United States in recent years. In 2007, approximately $18 \%$ of American adults reported using natural products beyond a basic multivitamin. ${ }^{3}$ Individuals use natural products for a variety of health reasons, including treating disease, preventing disease, maintaining health, and promoting wellness. The evidence base for this use is mixed and individuals do not use natural products in isolation. Many people use multiple natural products simultaneously and also engage in other health related behaviors, such as dietary changes, physical activity, and the use of medications to prevent and treat disease. Factors associated with the use of natural products include prior use of natural products, higher age, higher education, and higher income. ${ }^{4}$ There is a common perception that natural products are safe because they are "natural," but a natural product is not necessarily a safe product. ${ }^{5}$

Natural products are of particular interest as chemopreventive agents because of their potentially low toxicity profiles and potential effectiveness. ${ }^{6}$ The National Center for Complementary and Alternative Medicine defines natural products as dietary supplements and include vitamins, minerals, probiotics, and herbal medicines. ${ }^{3}$ The National Cancer Institute's Office for Cancer Complementary and Alternative Medicine (OCCAM) uses slightly different terminology for dietary supplements used as chemopreventive agents, referring to them as nutritional therapeutics, which include an assortment of nutrients, nonnutrients, and bioactive food components. ${ }^{7}$

The efficacy of natural products as chemopreventive agents for primary and tertiary cancer prevention has not yet been established. Observational studies have suggested that various vitamins, minerals and dietary components reduce the risk of developing specific cancers. However, clinical trials have not always supported these observations and/or the trials have not been conducted to test the efficacy of the natural products as chemopreventive agents. Current guidelines from the American Institute of Cancer Research, the American Cancer Society, and the Society for Integrative Oncology recommend against the use of dietary supplements for cancer prevention based on the current evidence. ${ }^{8-11}$ Many patients are not aware of these guidelines, or disregard the guidelines and use natural products with the intention of cancer prevention based on reports in the popular press and/or preliminary evidence.

Health care providers face many challenges when counseling patients on the use of natural products for cancer prevention. First, we know that patients underreport use to their health care providers. ${ }^{12}$ Reasons for this may include perceiving a lack of support for their use, or fear of stigma from providers. Second, many health care providers feel that they are not qualified or sufficiently knowledgeable to counsel patients on the use of natural products. ${ }^{13}$ Third, quality assurance of natural products is important. ${ }^{14}$ Because the natural product industry is not tightly regulated by the Food and Drug Administration (FDA), it can be challenging for health care providers to know whether a specific natural product is of high quality or not. Fourth, the evidence does not yet exist regarding the appropriate formulation, dose, duration, and cancer type for promising natural products.

This review provides an overview of commonly used natural products for cancer prevention, including a summary of the clinical trial literature to date. It is important to note upfront that many of the results presented in the tables are based upon post-hoc analyses, and are not the primary study outcomes, which may limit the generalizability and accuracy of the findings. 


\section{SUMMARY OF RESEARCH TO DATE}

\section{Vitamins and Minerals}

Clinical trials examining vitamins and minerals as chemopreventive agents are summarized in Table 1.

Multivitamins and combinations-Multivitamins and combination vitamins are dietary supplements comprised of two or more single agents. They are commonly used to both improve the nutritional status among nutrient deficient populations and to hyper-supplement nutrient replete populations. The results of clinical trials examining the effects of multivitamins as chemoprevention agents remain mixed. Intervention trials in Linxian, China revealed the importance of multivitamin supplementation in nutrition deficient populations to reduce the risk of esophageal, stomach and other cancers. ${ }^{15}$ The benefit of supplementation in nutrient replete populations is not as clear. The Supplementation en Vitamines et Mineraux Antioxydants (SU.VI.MAX) Trial showed that multivitamin use by men with normal PSA levels at baseline resulted in reduced prostate cancer incidence. Among men with elevated PSA levels at baseline however, multivitamin use was associated with a slightly increased prostate cancer incidence. ${ }^{16}$ The Physicians Health Study II, a large randomized clinical trial, continues to examine the effects of multivitamins in preventing prostate, colorectal and other cancers in healthy men (ClinicalTrials.gov NCT00270647). Of note, recent results from the Iowa Women's Health Study, a cohort study of older women, suggest that there is an increase in overall mortality with the use of multivitamins, vitamin B6, iron, magnesium, zinc and copper. ${ }^{17}$

\section{Single Agents}

Vitamin C: Vitamin C (ascorbic acid) is a water soluble antioxidant that is an essential nutrient for humans. All fruits and vegetables contain vitamin $\mathrm{C}$, with high concentrations found in citrus fruits, cruciferous vegetables and dark leafy greens. The dietary reference intake (DRI) estimated average requirement for women is $60 \mathrm{mg}$ per day and for men is 75 mg per day. ${ }^{18}$ Beginning in the 1970s Linus Pauling promoted the use of vitamin C to prevent the common cold, and later for the treatment of cancer. His results and claims remain controversial, but popular interest in vitamin $\mathrm{C}$ is still high. To date, clinical trials examining the effects of vitamin $C$ on cancer prevention have not shown benefit. ${ }^{19,20}$

Vitamin E: Vitamin E is a fat soluble antioxidant that acts as a free-radical scavenger. Nuts, seeds, vegetable oils and green leafy vegetables are food sources high in vitamin $\mathrm{E}$. The vitamin E DRI estimated average requirement is $12 \mathrm{mg} / 22.4 \mathrm{IU}$ per day and it is commonly found in multivitamin formulations. ${ }^{18}$ Thus far, clinical trials have shown no benefit of vitamin E as a chemoprevention agent. The Selenium and Vitamin E Cancer Prevention Trial (SELECT) found no benefit of vitamin E supplementation in men on the risk of prostate cancer and the trial was stopped early due to concern of vitamin E increasing prostate cancer risk. ${ }^{21,22}$ Recent updated results from the SELECT trial demonstrate that this concern was warranted. After 7 years mean follow-up, supplementation with 400 IUs of vitamin E significantly increased the risk of prostate cancer. ${ }^{23}$ Similarly, well-designed clinical trials among women have not shown benefit of vitamin $\mathrm{E}$ on the prevention of breast, lung or colon cancer. ${ }^{24,25}$

Selenium: Selenium is a necessary trace mineral involved in metabolism and is a potent antioxidant. Food sources high in selenium include Brazil nuts, brewers yeast, and vegetables grown in selenium-rich soil. Other food sources include fish, shellfish, red meat, grains, eggs, chicken and garlic. The current DRI for selenium in adults is $45 \mu \mathrm{g}$ per day. ${ }^{18}$ Results from the initial trials in Linxian, China led many to believe that selenium could be a 
beneficial chemopreventive agent. Additional trials in China reported that selenium supplementation lowered the risk of liver cancer incidence, ${ }^{26-28}$. However, results from clinical trials in the United States examining the effect of selenium supplementation on the incidence of cancer have been inconsistent. Early trials reported that selenium supplementation led to significant decrease in the incidence of prostate cancer, but more recent trials have reported no benefits from supplementation. ${ }^{21,22,29-31}$ The latest results from the SELECT trial however, report a possible increase in prostate cancer risk from selenium supplementation, although this increase did not reach statistical significance. ${ }^{23}$ The Nutritional Prevention of Cancer Trial (NPCT) aimed to examine the effect of selenium on the incidence of several cancers and total cancer mortality. While selenium supplementation did not reduce the incidence of nonmelanoma skin cancer, squamous or basal cell carcinoma, it was found to be protective against prostate, lung, and colorectal cancers, and significantly reduced total cancer incidence and total cancer mortality. ${ }^{30-33}$

Beta-Carotene: Beta-carotene, a nutrient found in leafy vegetables and fruit of yellow and orange pigment, is also an antioxidant and a free radical scavenger. Beta-carotene is also commonly found in multivitamin and combination antioxidant dietary supplement formulations. Observational studies have shown an inverse association between dietary betacarotene intake and lung cancer incidence in populations at high risk of developing lung cancer. ${ }^{34}$ Based on these observations, large scale clinical trials were conducted to determine the ability of supplemental beta-carotene to prevent lung cancer in high risk populations. ${ }^{35,36}$ Contrary to the study hypotheses, two trials ${ }^{36,37}$ conducted among smokers and asbestos workers showed increased rates of lung cancer among those who received betacarotene supplementation, and one of the trials also showed no significant difference in prostate cancer incidence. ${ }^{37}$ Beta-carotene showed no effect in clinical trials testing its efficacy in skin and colon cancer prevention. ${ }^{38,39}$ These findings suggest a cautious approach to translating observational findings to the clinical setting and reinforce the need for well conducted clinical trials to demonstrate the benefit or harm of natural products for cancer prevention. The U.S. Preventive Services Task Force has concluded that betacarotene supplementation is unlikely to provide important clinical benefits and that it may cause harm to some groups. ${ }^{40}$

Vitamin D: Vitamin D is a fat-soluble vitamin that functions as a prohormone and regulates bone metabolism. The two major forms of vitamin $\mathrm{D}$ are vitamin $\mathrm{D}_{3}$ (cholecalciferol) and vitamin $\mathrm{D}_{2}$ (ergocalciferol). Vitamin $\mathrm{D}_{3}$ is produced in the skin upon exposure to ultraviolet radiation. Dietary sources of vitamin D include fatty fish (salmon, mackerel, sardines) and mushrooms. The Institute of Medicine recently published a report recommending a daily dose of 600 IUs of vitamin D. ${ }^{41}$ A rapidly growing body of observational data suggests that higher vitamin $\mathrm{D}$ concentrations in the blood are associated with lower rates of multiple cancer types. ${ }^{42-45}$ It is currently unknown whether changing an individual's vitamin D concentration over time is beneficial, or at what point in the lifecourse this change may be important for cancer prevention. To date, the results of four clinical trials ${ }^{46-49}$ have been published on the effects of combined vitamin $\mathrm{D}$ and calcium supplementation on cancer incidence and/or mortality. Of these, only one trial reported a decrease in cancer incidence resulting from vitamin $\mathrm{D}$ and calcium supplementation. ${ }^{47}$ The other trials reported no impact on total cancer incidence, colorectal cancer, or cancer mortality resulting from combined vitamin D and calcium supplementation. ${ }^{46,48,49}$ Many clinical trials are ongoing to examine the effects of vitamin D supplementation on surrogate biomarkers for cancer as well as cancer incidence, some with doses as high as 25,000 IUs per week (ClinicalTrials.gov). The Vitamin D and Omega-3 Trial (VITAL) is an ongoing trial examining the effects of vitamin $\mathrm{D}$ and omega-3 supplementation in women on a host of outcomes, including cancer 
incidence (ClinicalTrials.gov, NCT01169259). Recruitment for the study began in January 2010 and is continuing through 2011.

\section{Botanicals}

Clinical trials examining botanicals as chemopreventive agents are described in Table 2.

Green tea-There is a great deal of interest in the chemopreventive effects of green tea (Camellia sinensis), particularly in the catechin polyphenols components. Epidemiologic studies suggest that green tea consumption may reduce the risk of upper gastrointestinal tract cancers, lung cancer, hepatocellular cancer, and breast cancer in premenopausal women. ${ }^{50,51}$ The most commonly studied polyphenol in the clinical trial setting is epigallocatechin-3gallate (EGCG) ${ }^{51}$ Green tea catechins act on multiple pathways, including oxidative stress, carcinogen elimination and enzyme inhibition. ${ }^{51}$ Green tea has historically been ingested as a tea, but chemoprevention applications typically use concentrated extracts. Currently there is no consensus on the necessary dose or duration of use. Pilot clinical trials of green tea have focused on effects on surrogate biomarkers, and have suggested potential benefit in oral, skin, cervical and prostate cancer prevention ${ }^{52-56}$; these results need to be replicated. Trials are ongoing on the use of green tea for breast cancer prevention (www.ClinicalTrials.gov NCT00917735, NCT00676793).

Soy-Soy, a complete protein source regarded as a staple of the East Asian diet, contains isoflavones which are of chemopreventive interest for their phytoestrogenic and antioxidant effects. Soy isoflavones can be administered via powder, extract or in food and there is no standardized dose. The clinical trial evidence for soy as an effective chemopreventive strategy in food or supplement form has been mixed. There has been great interest in the use of soy for primary breast cancer prevention, but little evidence thus far suggesting an effect. ${ }^{57}$ There have been concerns of soy phytoestrogens acting as tumor promoters after a breast cancer diagnosis; a recent editorial suggests that this need not be a concern. ${ }^{58}$ Studies on the effects of soy isoflavones on prostate cancer biomarkers, including prostate serum antigen (PSA), have yielded mixed results. ${ }^{59-61}$ An early phase study suggested that soy may decrease tumor progression in patients with low-grade prostate cancer. ${ }^{62}$

Curcumin-Curcumin, also known as turmeric or Curcuma longa, is a root commonly used as a culinary spice and is a major component of curry powders. Curcuminoids are the bioactive components of particular interest in chemoprevention for their antioxidant and anti-inflammatory effects, as well as their ability to inhibit activation of carcinogens by cytochrome enzymes. ${ }^{63}$ There is no standardized dose at this time and routes of administration can be via encapsulated powder, extracts, or in food. Curcumin is poorly absorbed and most of the research to date has focused on colorectal cancer prevention because of the direct contact with the colonic mucosa. There are limited clinical trial data. A primary prevention study suggests that curcumin may prevent the development of aberrant crypt foci in populations at high risk of colorectal cancer. ${ }^{64} \mathrm{~A}$ small study in patients with adenomas suggested a possible reduction of polyp size and number with curcumin administration, whereas a study among patients with advanced colorectal cancer showed little effect on preventing disease progression. ${ }^{65,66}$

\section{Fish Oil, Medicinal Mushromms and Probiotics}

A summary of clinical trials examining the use of fish oil, medicinal mushsrooms and probiotics are found in Table 3.

Fish Oils-Omega-3 fatty acids, such as docosahexaenoic acid (DHA) and eicosapentaenoic acid (EPA), are polyunsaturated fatty acids contained in fish oils. These 
compounds have been shown to have cardioprotective effects and are of interest for cancer prevention for their ability to inhibit the formation of proinflammatory and procarcinogenic eicosanoids, such as prostaglandins. Typical doses range from one to four grams per day and are usually ingested via capsules or liquid form. Clinical trials to date suggest that EPA and DHA may protect against colorectal cancer in high risk populations. ${ }^{67,68}$ The Vitamin D and Omega-3 Trial (VITAL) is an ongoing trial assessing the potential benefits of fish oil supplementation on overall cancer risk (www.ClinicalTrials.gov NCT01169259).

Medicinal Mushrooms-Medicinal mushrooms, including Ganoderma lucidum, Coriolus versicolor, and maitake Grifola frondosa), are commonly found in Asian traditional pharmacopeias. Medicinal mushrooms may exert chemopreventive effects through their polysaccharides, which have been shown to enhance immune function, as well as their secondary metabolites, which may affect pathways related to apoptosis, angiogenesis, metastasis, cell cycle regulation, and signal transduction cascades. ${ }^{69}$ Medicinal mushrooms are commonly ingested via encapsulated powders, extracts and teas. The clinical trial research is in the early stages and preliminary studies have shown protective benefits including increasing immune function, and preventing recurrence. ${ }^{70-72}$

\section{Probiotics}

Probiotics, such as Lactobacillus sp., are live microorganisms found in dietary supplements and fermented food sources, such as yogurt and kefir, which possess possible chemopreventive benefits for the gastrointestinal tract. ${ }^{73}$ Doses vary depending on the type of organism and are typically quantified by the number of living organisms per capsule, or colony forming unit (CFU) per capsule. Probiotics are hypothesized to confer their chemopreventive benefit by altering the gut microbiota and subsequently inhibiting/inducing colonic enzyme systems, controlling growth of harmful bacteria, improving immune function, and stimulating the production of active anticancer metabolites. In a trial of patients with a history of colorectal cancer, the occurrence of tumors with moderate and severe atypia was lower in the group receiving L.casei supplementation. ${ }^{74}$ A clinical trial among healthy individuals suggested increased immune response with probiotics. ${ }^{75}$ More research is needed to fully understand the chemopreventive role of probiotics.

\section{IMPLICATIONS FOR ONCOLOGY CLINICIANS}

Individuals use natural products for a variety of reasons, including cancer prevention and preventing cancer recurrence. It is important for health care providers to discuss use of natural products with their patients so that they can be counseled appropriately. Towards this aim, algorithms and guidelines have been developed for clinicians to use when counseling patient on the use of natural products and other complementary therapies. ${ }^{76,77}$ There are a number of reputable online resources for health care providers to use to investigate specific natural products including the National Center for Complementary and Alternative Medicine (www.nccam.nih.gov), the National Cancer Institute's Office of Cancer Complementary and Alternative Medicine (www.cancer.gov/cam), US National Library of Medicine (www.nlm.nih.gov/medlineplus), American Institute for Cancer Research (www.aicr.org) and Natural Medicines Comprehensive Database (www.naturaldatabase.therapeuticresearch.com).

Based on evidence to date, it is not possible to recommend specific natural products as reliable and effective chemoprevention strategies. Clinicians should encourage their patients to use proven chemoprevention strategies and to follow lifestyle modifications to reduce their cancer risk. See Table 4 for a list of the most recent cancer prevention strategies published by the American Institute of Cancer Research. ${ }^{78}$ 
Clinicians can also suggest that their patients participate in clinical trials, when appropriate, in order to build the evidence base. Ongoing trials can be found at www.ClinicalTrials.gov.

For patients who are already using natural products, clinicians can inquire about their motivation for use, and counsel them using the current recommendations. Many patients use natural products with the goal of maintaining and/or improving overall health and wellness. This can be a good opportunity to discuss the benefits of other healthy behaviors, such as cancer screening, maintaining a healthy diet, being physically active, and maintaining a healthy body size.

For patients who chose to use natural products, clinicians can advise them to use high quality products that are produced under high levels of quality assurance, though this can be difficult to do given that the natural product industry is not regulated.

\section{IMPLICATIONS FOR SPECIAL POPULATIONS}

Special populations, including individuals at high risk of developing cancer, individuals receiving cancer treatment, and individuals who have completed treatment, commonly use natural products. There is limited evidence to date on the effectiveness of natural products preventing cancer or cancer recurrence. Certain populations, including pediatric and geriatric populations, may be high users of natural products, using natural products for other health concerns. These patients should be counseled on potential effects, lack of effects, as well as drug interactions. Reliable resources for clinicians include National Center for Complementary and Alternative Medicine (www.nccam.nih.gov), the National Cancer Institute's Office of Cancer Complementary and Alternative Medicine (www.cancer.gov/ cam) and Natural Medicines Comprehensive Database (www.naturaldatabase.therapeuticresearch.com).

\section{Conclusion}

There is great potential for specific dietary supplements to be effective chemopreventive agents. However, to date some agents have shown promise while others have not. No agents have been proven to be effective against all cancers, and it is highly unlikely that such an agent will be identified. Until stronger evidence exists, clinicians can encourage their patients to engage in other healthy behaviors, including cancer screening, maintaining a healthy diet, achieving a healthy body size and being physically active.

\section{Acknowledgments}

The author thanks Ms. Alexis Kral, Ms. Cristina Valdovinos and Ms. Lola Arakaki for their assistance in manuscript preparation. The content of this manuscript is solely the responsibility of the author and does not necessarily represent the official views of the National Cancer Institute.

Funding support: Dr. Greenlee receives support from the National Cancer Institute (K23CA141052).

\section{References}

1. SEER Cancer Statistics Review, 1975-2008. Bethesda, MD: National Cancer Institute; 2010.

2. Alberts, DS.; Hess, LM. Fundamentals of Cancer Prevention. New York: Springer; 2005.

3. [Accessed September 1, 2011] What is Complementary and Alternative Medicine?. 2008. http:// nccam.nih.gov/health/whatiscam/

4. Barnes PM, Bloom B, Nahin RL. Complementary and alternative medicine use among adults and children: United States, 2007. Natl Health Stat Report. Dec 10.2008 (12):1-23. [PubMed: 19361005] 
5. [Accessed September 1, 2011.] Thinking About Complementary and Alternative Medicine: A Guide for People With Cancer. 2011. http://www.cancer.gov/cancertopics/cam/thinking-about-CAM/ page7

6. Crowell JA. The chemopreventive agent development research program in the Division of Cancer Prevention of the US National Cancer Institute: an overview. Eur J Cancer. Sep; 2005 41(13):18891910. [PubMed: 16005206]

7. [Accessed September 1, 2011.] Categories of CAM Therapies. http://www.cancer.gov/cam/ health_categories.html

8. Glade MJ. Food, nutrition, and the prevention of cancer: a global perspective. American Institute for Cancer Research/World Cancer Research Fund, American Institute for Cancer Research, 1997. Nutrition. Jun; 1999 15(6):523-526. [PubMed: 10378216]

9. Doyle C, Kushi LH, Byers T, et al. Nutrition and physical activity during and after cancer treatment: an American Cancer Society guide for informed choices. CA Cancer J Clin. Nov-Dec;2006 56(6): 323-353. [PubMed: 17135691]

10. Kushi LH, Byers T, Doyle C, et al. American Cancer Society Guidelines on Nutrition and Physical Activity for cancer prevention: reducing the risk of cancer with healthy food choices and physical activity. CA Cancer J Clin. Sep-Oct;2006 56(5):254-281. quiz 313-254. [PubMed: 17005596]

11. Deng GE, Frenkel M, Cohen L, et al. Evidence-based clinical practice guidelines for integrative oncology: complementary therapies and botanicals. J Soc Integr Oncol. Summer;2009 7(3):85120. [PubMed: 19706235]

12. Saydah SH, Eberhardt MS. Use of complementary and alternative medicine among adults with chronic diseases: United States 2002. J Altern Complement Med. Oct; 2006 12(8):805-812. [PubMed: 17034287]

13. Wahner-Roedler DL, Vincent A, Elkin PL, Loehrer LL, Cha SS, Bauer BA. Physicians' attitudes toward complementary and alternative medicine and their knowledge of specific therapies: a survey at an academic medical center. Evid Based Complement Alternat Med. Dec; 2006 3(4): 495-501. [PubMed: 17173114]

14. [Accessed September 23 2011.] Dietary Supplements. 2011. http://www.fda.gov/Food/ DietarySupplements/default.htm

15. Blot WJ, Li JY, Taylor PR, et al. Nutrition intervention trials in Linxian, China: supplementation with specific vitamin/mineral combinations, cancer incidence, and disease-specific mortality in the general population. J Natl Cancer Inst. Sep 15; 1993 85(18):1483-1492. [PubMed: 8360931]

16. Meyer F, Galan P, Douville P, et al. Antioxidant vitamin and mineral supplementation and prostate cancer prevention in the SU.VI.MAX trial. Int J Cancer. Aug 20; 2005 116(2):182-186. [PubMed: 15800922]

17. Murso J, Robien K, Harnack LJ, Park K Jr, DRJ. Dietary Supplements and Mortality Rate in Older Women. Archives of Internal Medicine. 2011; 171(18):1625-1633. [PubMed: 21987192]

18. Dietary Reference Intake (DRIs). Estimated Average Requirements 2011. 2011. [Accessed Septemeber 16, 2011.]

19. Moertel CG, Fleming TR, Creagan ET, Rubin J, O’Connell MJ, Ames MM. High-dose vitamin C versus placebo in the treatment of patients with advanced cancer who have had no prior chemotherapy. A randomized double-blind comparison. N Engl J Med. Jan 17; 1985 312(3):137141. [PubMed: 3880867]

20. Gaziano JM, Glynn RJ, Christen WG, et al. Vitamins E and C in the prevention of prostate and total cancer in men: the Physicians' Health Study II randomized controlled trial. JAMA. Jan 7; 2009 301(1):52-62. [PubMed: 19066368]

21. Lippman SM, Klein EA, Goodman PJ, et al. Effect of selenium and vitamin E on risk of prostate cancer and other cancers: the Selenium and Vitamin E Cancer Prevention Trial (SELECT). JAMA. Jan 7; 2009 301(1):39-51. [PubMed: 19066370]

22. Dunn BK, Richmond ES, Minasian LM, Ryan AM, Ford LG. A nutrient approach to prostate cancer prevention: The Selenium and Vitamin E Cancer Prevention Trial (SELECT). Nutr Cancer. 2010; 62(7):896-918. [PubMed: 20924966] 
23. Klein EA Jr, IMT, Tangen CM, et al. Vitamin E and the risk of prostate cancer: the Selenium and Vitamin E Cancer Prevention Trial (SELECT). American Medical Association. 2011; 306(14): 1549-1556.

24. Lonn E, Bosch J, Yusuf S, et al. Effects of long-term vitamin E supplementation on cardiovascular events and cancer: a randomized controlled trial. JAMA. Mar 16; 2005 293(11):1338-1347. [PubMed: 15769967]

25. Lee IM, Cook NR, Gaziano JM, et al. Vitamin E in the primary prevention of cardiovascular disease and cancer: the Women's Health Study: a randomized controlled trial. JAMA. Jul 6; 2005 294(1):56-65. [PubMed: 15998891]

26. Yu SY, Zhu YJ, Li WG, et al. A preliminary report on the intervention trials of primary liver cancer in high-risk populations with nutritional supplementation of selenium in China. Biol Trace Elem Res. Jun; 1991 29(3):289-294. [PubMed: 1726411]

27. Yu SY, Zhu YJ, Li WG. Protective role of selenium against hepatitis B virus and primary liver cancer in Qidong. Biol Trace Elem Res. Jan; 1997 56(1):117-124. [PubMed: 9152515]

28. Li W, Zhu Y, Yan X, et al. The prevention of primary liver cancer by selenium in high risk populations. Zhonghua Yu Fang Yi Xue Za Zhi. Nov; 2000 34(6):336-338. [PubMed: 11860943]

29. Dennert G, Zwahlen M, Brinkman M, Vinceti M, Zeegers MP, Horneber M. Selenium for preventing cancer. Cochrane Database Syst Rev. 2011; 5:CD005195. [PubMed: 21563143]

30. Clark L, Combs G Jr, Turnbull B, et al. Effects of selenium supplementation for cancer prevention in patients with carcinoma of the skin. A randomized controlled trial. Nutritional Prevention of Cancer Study Group. JAMA. 1996; 276(24):1957-1963. [PubMed: 8971064]

31. Clark LC, Dalkin B, Krongrad A, et al. Decreased incidence of prostate cancer with selenium supplementation: results of a double-blind cancer prevention trial. Br J Urol. May; 1998 81(5): 730-734. [PubMed: 9634050]

32. Duffield-Lillico AJ, Slate EH, Reid ME, et al. Selenium supplementation and secondary prevention of nonmelanoma skin cancer in a randomized trial. J Natl Cancer Inst. Oct 1; 2003 95(19):1477_ 1481. [PubMed: 14519754]

33. Reid ME, Duffield-Lillico AJ, Slate E, et al. The nutritional prevention of cancer: 400 mcg per day selenium treatment. Nutr Cancer. 2008; 60(2):155-163. [PubMed: 18444146]

34. Ziegler RG. A review of epidemiologic evidence that carotenoids reduce the risk of cancer. The Journal of Nutrition. 1989; 119(1):116-122. [PubMed: 2643694]

35. Heinonen OP, Albanes D. The effect of vitamin $\mathrm{E}$ and beta carotene on the incidence of lung cancer and other cancers in male smokers. N Engl J Med. Apr 14; 1994 330(15):1029-1035. [PubMed: 8127329]

36. Omenn GS, Goodman GE, Thornquist MD, et al. Effects of a combination of beta carotene and vitamin A on lung cancer and cardiovascular disease. N Engl J Med. May 2; 1996 334(18):1150_ 1155. [PubMed: 8602180]

37. Heinonen OP, Albanes D, Virtamo J, et al. Prostate cancer and supplementation with alphatocopherol and beta-carotene: incidence and mortality in a controlled trial. J Natl Cancer Inst. Mar 18; 1998 90(6):440-446. [PubMed: 9521168]

38. Greenberg ER, Baron JA, Stukel TA, et al. A clinical trial of beta carotene to prevent basal-cell and squamous-cell cancers of the skin. The Skin Cancer Prevention Study Group. N Engl J Med. Sep 20; 1990 323(12):789-795. [PubMed: 2202901]

39. Albanes D, Malila N, Taylor PR, et al. Effects of supplemental alpha-tocopherol and beta-carotene on colorectal cancer: results from a controlled trial (Finland). Cancer Causes Control. Mar; 2000 11(3):197-205. [PubMed: 10782653]

40. Guirguis-Blake J. Routine vitamin supplementation to prevent cancer and cardiovascular disease. Am Fam Physician. Aug 1; 2004 70(3):559-560. [PubMed: 15317443]

41. Ross AC, Manson JE, Abrams SA, et al. The 2011 Dietary Reference Intakes for Calcium and Vitamin D: what dietetics practitioners need to know. J Am Diet Assoc. Apr; 2011 111(4):524527. [PubMed: 21443983]

42. McCullough ML, Robertson AS, Rodriguez C, et al. Calcium, vitamin D, dairy products, and risk of colorectal cancer in the Cancer Prevention Study II Nutrition Cohort (United States). Cancer Causes Control. Feb; 2003 14(1):1-12. [PubMed: 12708719] 
43. Jenab M, Bueno-de-Mesquita HB, Ferrari P, et al. Association between pre-diagnostic circulating vitamin D concentration and risk of colorectal cancer in European populations: a nested casecontrol study. BMJ. 2010; 340:b5500. [PubMed: 20093284]

44. Jacobs ET, Thomson CA, Flatt SW, et al. Vitamin D and breast cancer recurrence in the Women's Healthy Eating and Living (WHEL) Study. Am J Clin Nutr. Jan; 2011 93(1):108-117. [PubMed: 20980485]

45. Edvardsen K, Veierod M, Brustad M, Braaten T, Engelsen O, Lund E. Vitamin D-effective solar UV radiation, dietary vitamin D and breast cancer risk. Int J Cancer. Mar 15; 2011 128(6):14251433. [PubMed: 20473950]

46. Trivedi DP, Doll R, Khaw KT. Effect of four monthly oral vitamin D3 (cholecalciferol) supplementation on fractures and mortality in men and women living in the community: randomised double blind controlled trial. British Medical Journal. 2003; 326(469)

47. Lappe JM, Travers-Gustafson D, Davies KM, Recker RR, Heaney RP. Vitamin D and calcium supplementation reduces cancer risk: results of a randomized trial. American Journal of Clinical Nutrition. 2007; 85(6):1586-1591. [PubMed: 17556697]

48. Wactawski-Wende J, Kotchen JM, Anderson GL, et al. Calcium plus vitamin D supplementation and the risk of colorectal cancer. N Engl J Med. Feb 16; 2006 354(7):684-696. [PubMed: 16481636]

49. Brunner RL, Wactawski-Wende J, Caan BJ, et al. The Effect of Calcium plus Vitamin D on Risk for Invasive Cancer: Results of the Women's Health Initiative (WHI) Calcium Plus Vitamin D Randomized Clinical Trial. Nutrition and Cancer. 2011; 63(6):827-841. [PubMed: 21774589]

50. Yuan JM, Sun C, Butler LM. Tea and cancer prevention: epidemiological studies. Pharmacol Res. Aug; 2011 64(2):123-135. [PubMed: 21419224]

51. Yang CS, Wang X. Green tea and cancer prevention. Nutr Cancer. 2010; 62(7):931-937. [PubMed: 20924968]

52. Katiyar SK, Perez A, Mukhtar H. Green tea polyphenol treatment to human skin prevents formation of ultraviolet light B-induced pyrimidine dimers in DNA. Clin Cancer Res. Oct; 2000 6(10):3864-3869. [PubMed: 11051231]

53. Jatoi A, Ellison N, Burch PA, et al. A phase II trial of green tea in the treatment of patients with androgen independent metastatic prostate carcinoma. Cancer. Mar 15; 2003 97(6):1442-1446. [PubMed: 12627508]

54. Choan E, Segal R, Jonker D, et al. A prospective clinical trial of green tea for hormone refractory prostate cancer: an evaluation of the complementary/alternative therapy approach. Urol Oncol. Mar-Apr;2005 23(2):108-113. [PubMed: 15869995]

55. Bettuzzi S, Brausi M, Rizzi F, Castagnetti G, Peracchia G, Corti A. Chemoprevention of human prostate cancer by oral administration of green tea catechins in volunteers with high-grade prostate intraepithelial neoplasia: a preliminary report from a one-year proof-of-principle study. Cancer Res. Jan 15; 2006 66(2):1234-1240. [PubMed: 16424063]

56. Tsao AS, Liu D, Martin J, et al. Phase II randomized, placebo-controlled trial of green tea extract in patients with high-risk oral premalignant lesions. Cancer Prev Res (Phila). Nov; 2009 2(11): 931-941. [PubMed: 19892663]

57. Kumar N, Allen K, Riccardi D, Kazi A, Heine J. Isoflavones in breast cancer chemoprevention: where do we go from here? Front Biosci. Sep 1.2004 9:2927-2934. [PubMed: 15353326]

58. Messina M, Abrams DI, Hardy M. Can clinicians now assure their breast cancer patients that soy foods are safe? Womens Health (Lond Engl). May; 2010 6(3):335-338. [PubMed: 20426596]

59. Adams KF, Chen C, Newton KM, Potter JD, Lampe JW. Soy isoflavones do not modulate prostate-specific antigen concentrations in older men in a randomized controlled trial. Cancer Epidemiol Biomarkers Prev. Apr; 2004 13(4):644-648. [PubMed: 15066931]

60. deVere White RW, Hackman RM, Soares SE, Beckett LA, Li Y, Sun B. Effects of a genistein-rich extract on PSA levels in men with a history of prostate cancer. Urology. Feb; 2004 63(2):259-263. [PubMed: 14972467]

61. Kumar NB, Cantor A, Allen K, et al. The specific role of isoflavones in reducing prostate cancer risk. Prostate. May 1; 2004 59(2):141-147. [PubMed: 15042614] 
62. Hamilton-Reeves JM, Rebello SA, Thomas W, Kurzer MS, Slaton JW. Effects of soy protein isolate consumption on prostate cancer biomarkers in men with HGPIN, ASAP, and low-grade prostate cancer. Nutr Cancer. 2008; 60(1):7-13. [PubMed: 18444130]

63. Shureiqi I, Baron JA. Curcumin chemoprevention: the long road to clinical translation. Cancer Prev Res (Phila). Mar; 2011 4(3):296-298. [PubMed: 21372027]

64. Carroll RE, Benya RV, Turgeon DK, et al. Phase IIa clinical trial of curcumin for the prevention of colorectal neoplasia. Cancer Prev Res (Phila). Mar; 2011 4(3):354-364. [PubMed: 21372035]

65. Cruz-Correa M, Shoskes DA, Sanchez P, et al. Combination treatment with curcumin and quercetin of adenomas in familial adenomatous polyposis. Clin Gastroenterol Hepatol. Aug; 2006 4(8):1035-1038. [PubMed: 16757216]

66. Sharma RA, McLelland HR, Hill KA, et al. Pharmacodynamic and pharmacokinetic study of oral Curcuma extract in patients with colorectal cancer. Clin Cancer Res. Jul; 2001 7(7):1894-1900. [PubMed: 11448902]

67. Bartoli GM, Palozza P, Marra G, et al. n-3 PUFA and alpha-tocopherol control of tumor cell proliferation. Mol Aspects Med. 1993; 14(3):247-252. [PubMed: 8264339]

68. West NJ, Clark SK, Phillips RK, et al. Eicosapentaenoic acid reduces rectal polyp number and size in familial adenomatous polyposis. Gut. Jul; 2010 59(7):918-925. [PubMed: 20348368]

69. Zaidman BZ, Yassin M, Mahajna J, Wasser SP. Medicinal mushroom modulators of molecular targets as cancer therapeutics. Appl Microbiol Biotechnol. Jun; 2005 67(4):453-468. [PubMed: 15726350]

70. Mitomi T, Tsuchiya S, Iijima N, et al. Randomized, controlled study on adjuvant immunochemotherapy with PSK in curatively resected colorectal cancer. The Cooperative Study Group of Surgical Adjuvant Immunochemotherapy for Cancer of Colon and Rectum (Kanagawa). Dis Colon Rectum. Feb; 1992 35(2):123-130. [PubMed: 1735313]

71. Gao Y, Zhou S, Jiang W, Huang M, Dai X. Effects of ganopoly (a Ganoderma lucidum polysaccharide extract) on the immune functions in advanced-stage cancer patients. Immunol Invest. Aug; 2003 32(3):201-215. [PubMed: 12916709]

72. Kodama N, Komuta K, Nanba H. Effect of Maitake (Grifola frondosa) D-Fraction on the activation of NK cells in cancer patients. J Med Food. Winter;2003 6(4):371-377. [PubMed: 14977447]

73. Davis CD, Milner JA. Gastrointestinal microflora, food components and colon cancer prevention. J Nutr Biochem. Oct; 2009 20(10):743-752. [PubMed: 19716282]

74. Ishikawa H, Akedo I, Otani T, et al. Randomized trial of dietary fiber and Lactobacillus casei administration for prevention of colorectal tumors. Int J Cancer. Sep 20; 2005 116(5):762-767. [PubMed: 15828052]

75. Klein A, Friedrich U, Vogelsang H, Jahreis G. Lactobacillus acidophilus 74-2 and Bifidobacterium animalis subsp lactis DGCC 420 modulate unspecific cellular immune response in healthy adults. Eur J Clin Nutr. May; 2008 62(5):584-593. [PubMed: 17440520]

76. Decker, G. Integrating Complementary and Alternative Medicine Therapies into an Oncology Practice: A Short History of Medicine. In: Buschel, PC.; Yarbro, CH., editors. Oncology nursing in the ambulatory setting: issues and models of care. 2. London: Jones and Bartlett Publishers; 2005. p. 365

77. Weiger WA, Smith M, Boon H, Richardson MA, Kaptchuk TJ, Eisenberg DM. Advising patients who seek complementary and alternative medical therapies for cancer. Ann Intern Med. Dec 3; 2002 137(11):889-903. [PubMed: 12458989]

78. Lee IM, Cook NR, Manson JE, Buring JE, Hennekens CH. Beta-carotene supplementation and incidence of cancer and cardiovascular disease: the Women's Health Study. J Natl Cancer Inst. Dec 15; 1999 91(24):2102-2106. [PubMed: 10601381]

79. Food, Nutrition, Physical Activity, and the Prevention of Cancer: a Global Perspective. Washington, DC: World Cancer Research Fund/American Institute for Cancer Research; 2007. 


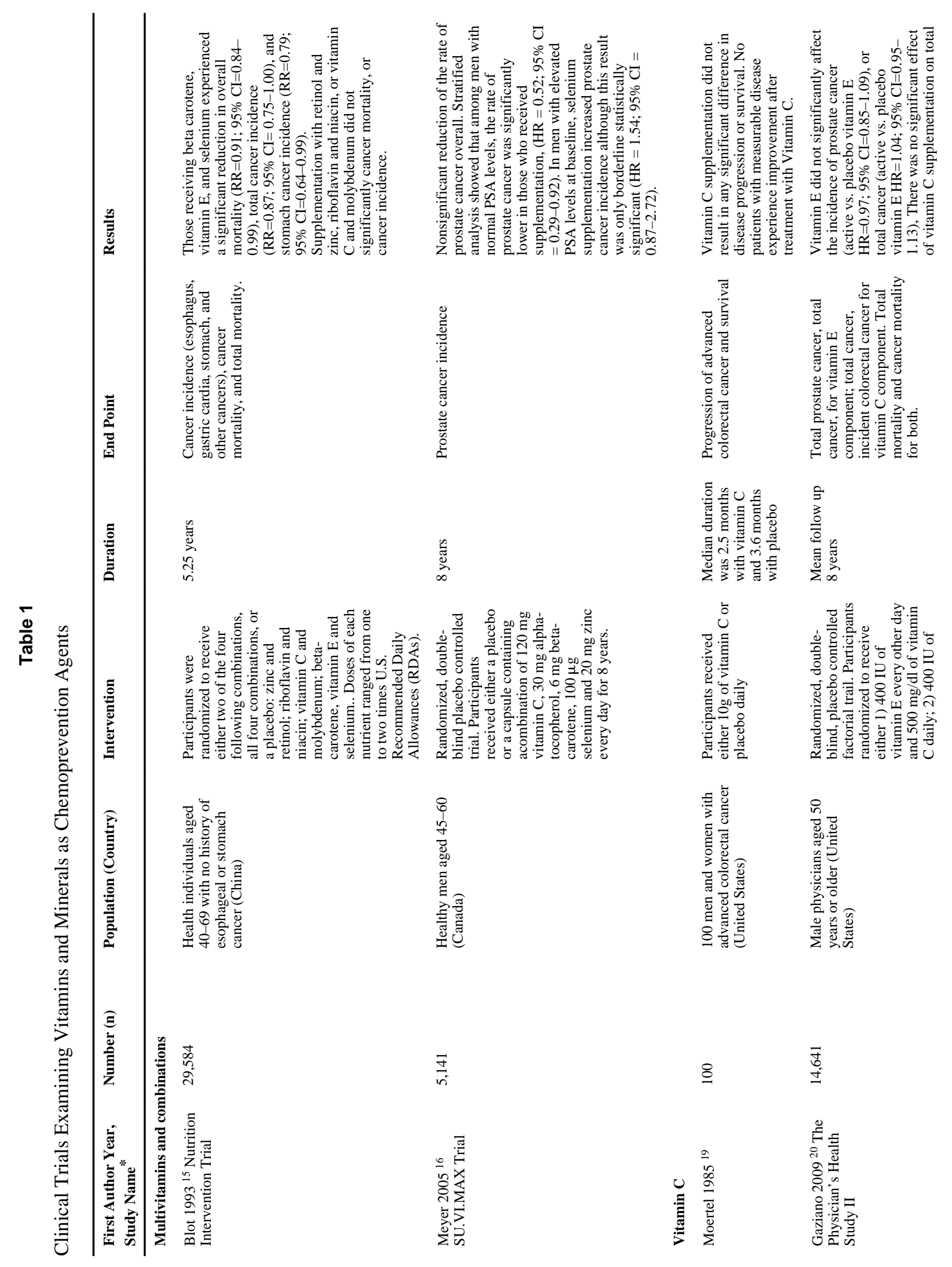

Semin Oncol Nurs. Author manuscript; available in PMC 2013 August 21. 


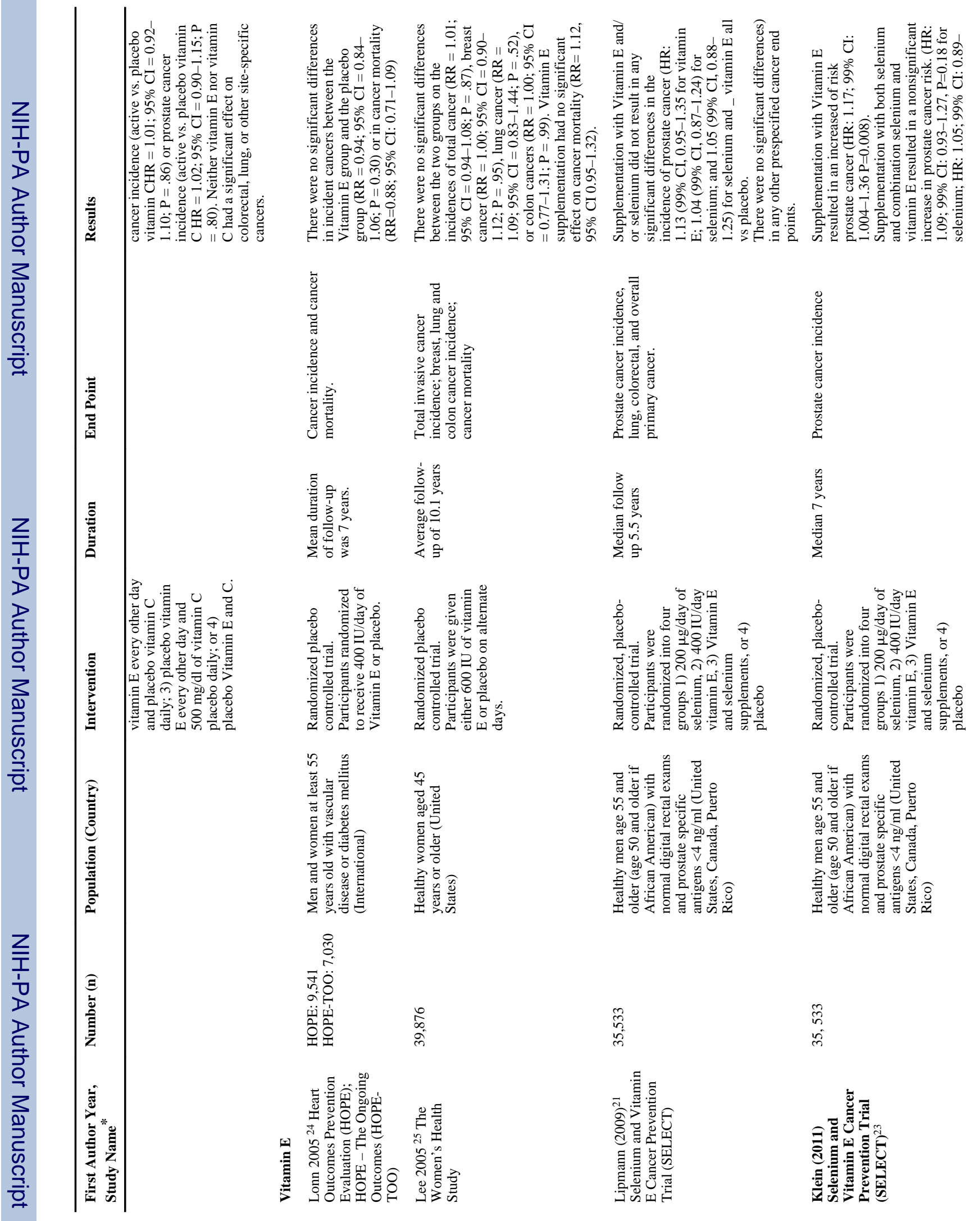




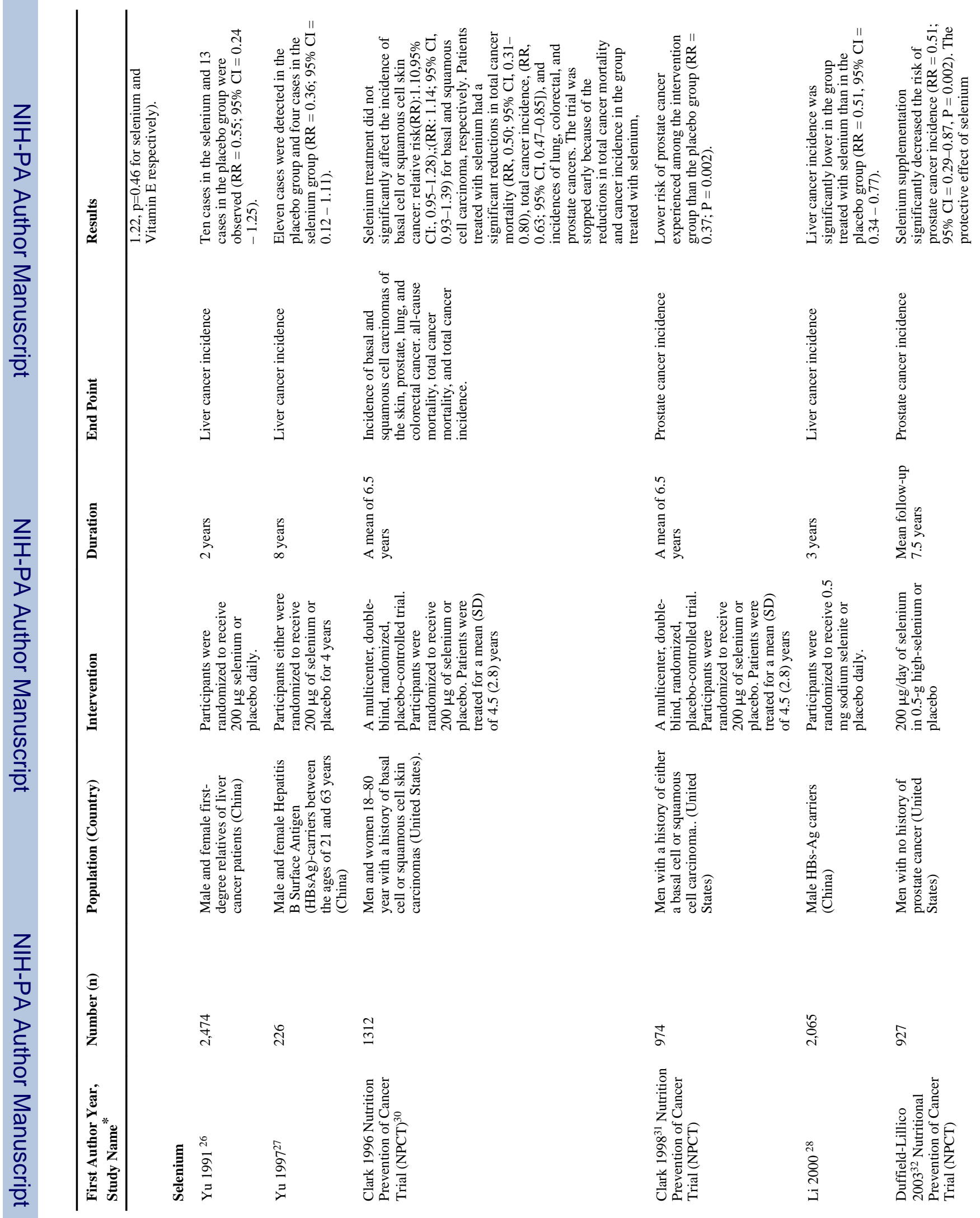




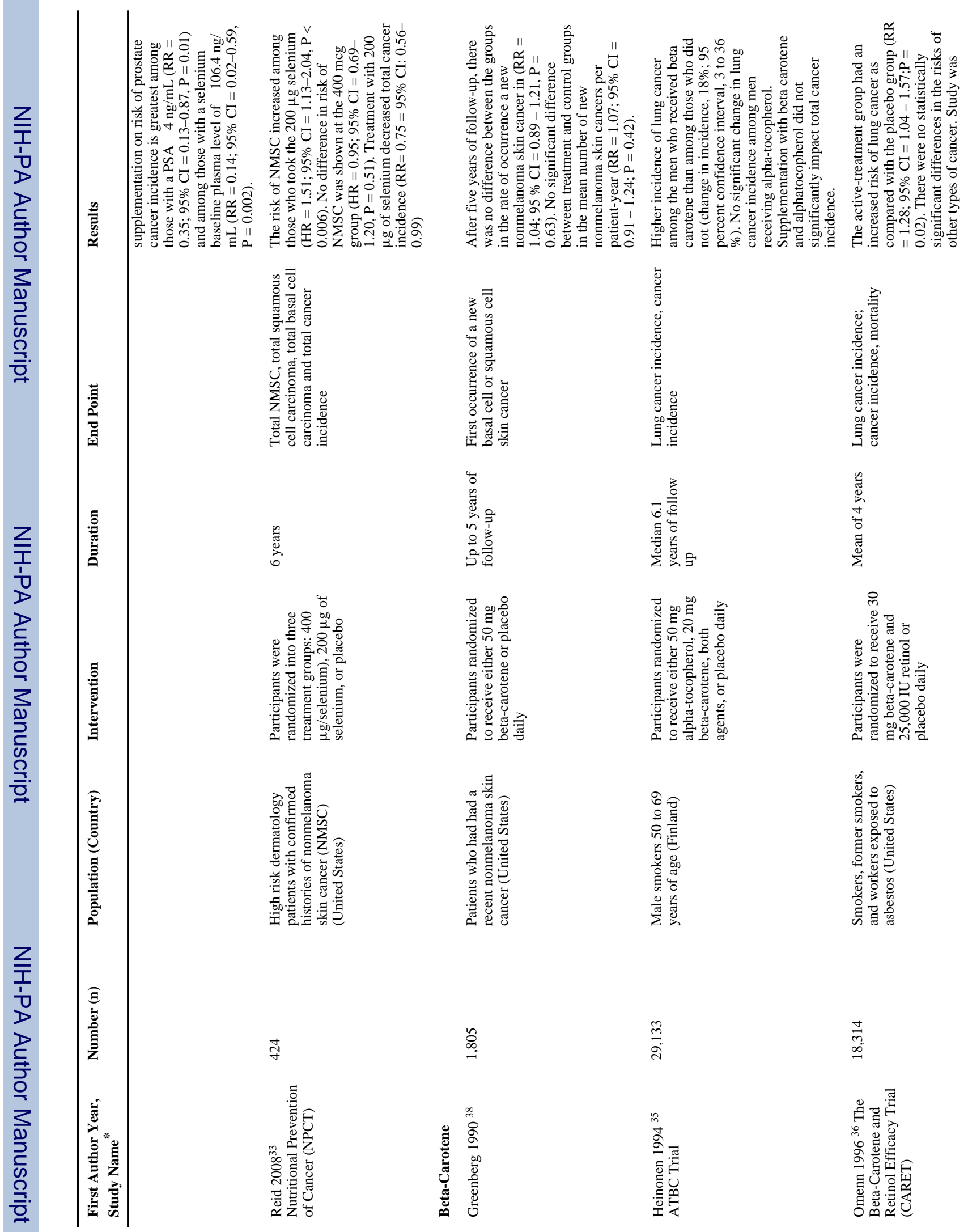

Semin Oncol Nurs. Author manuscript; available in PMC 2013 August 21. 


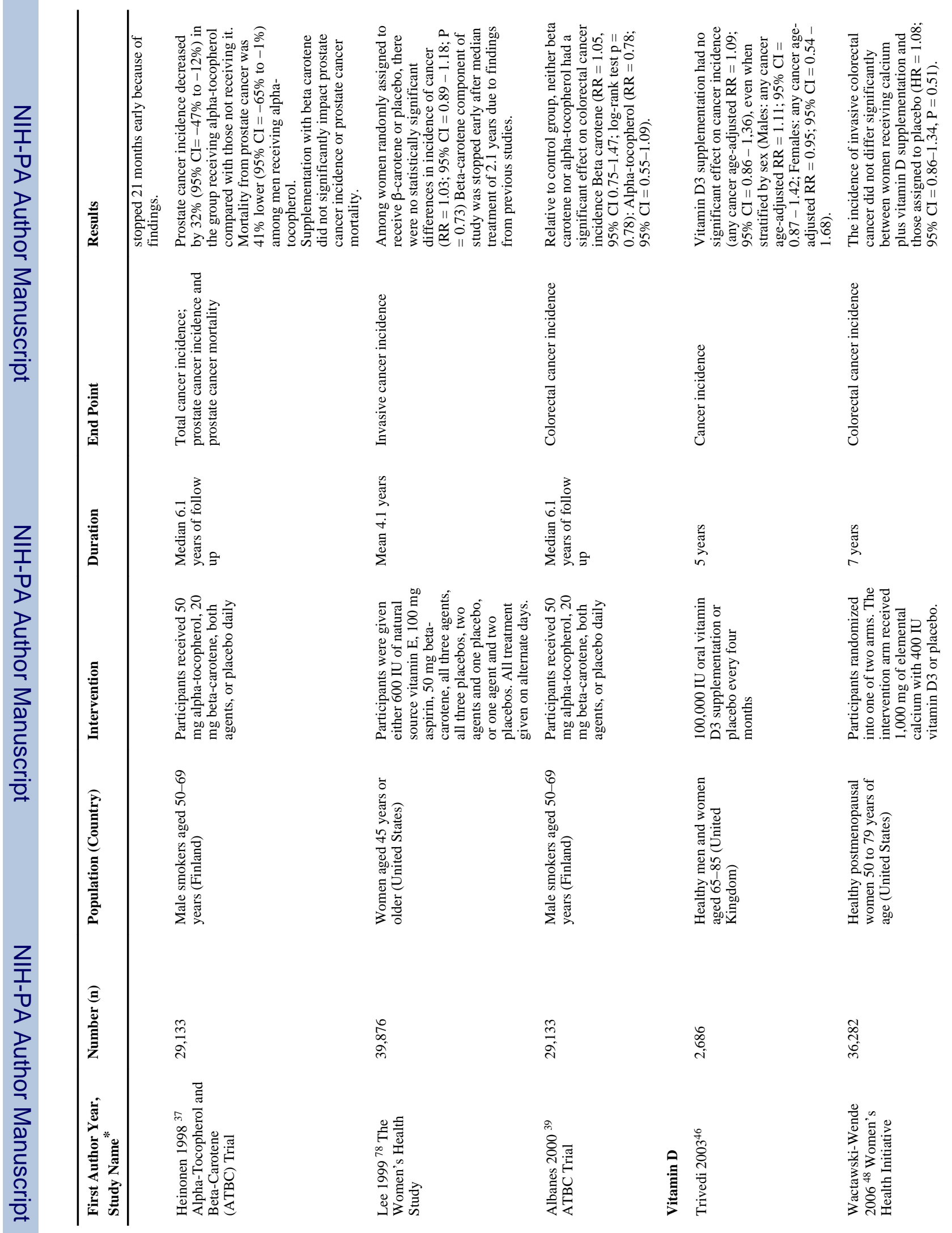




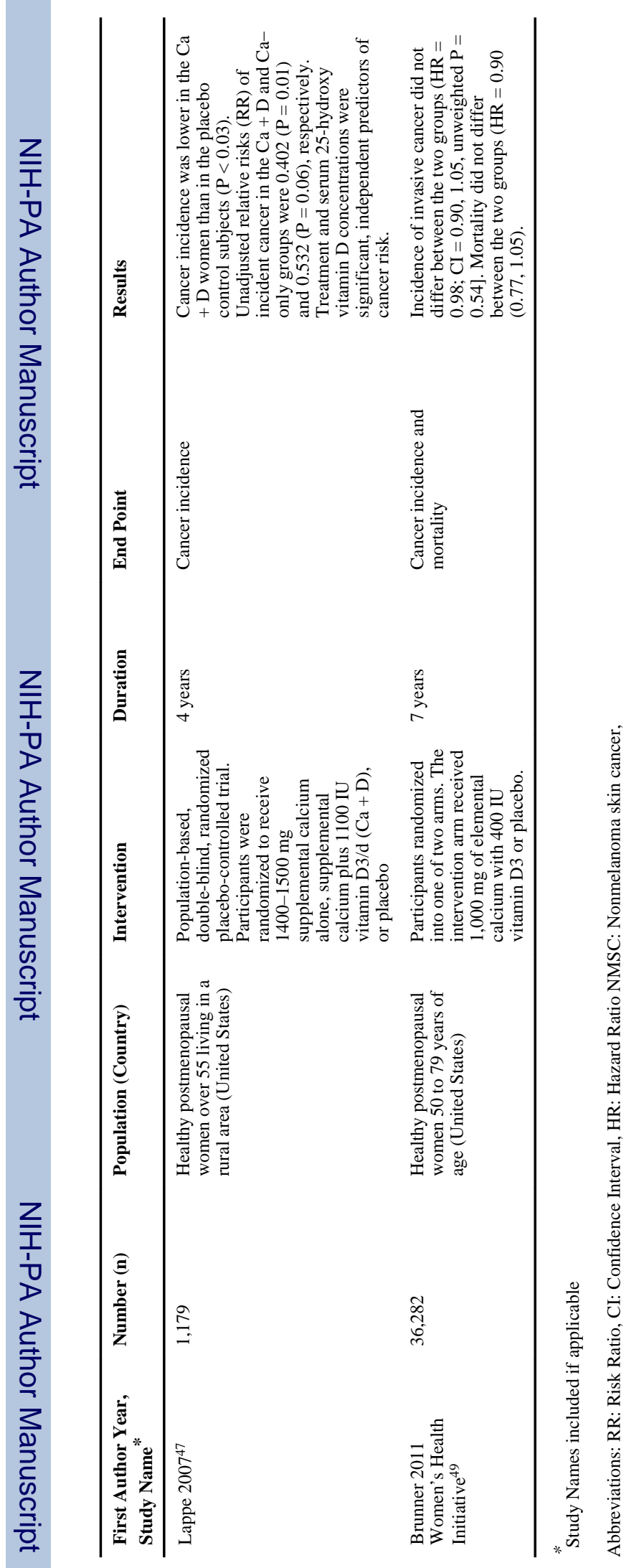

Semin Oncol Nurs. Author manuscript; available in PMC 2013 August 21. 

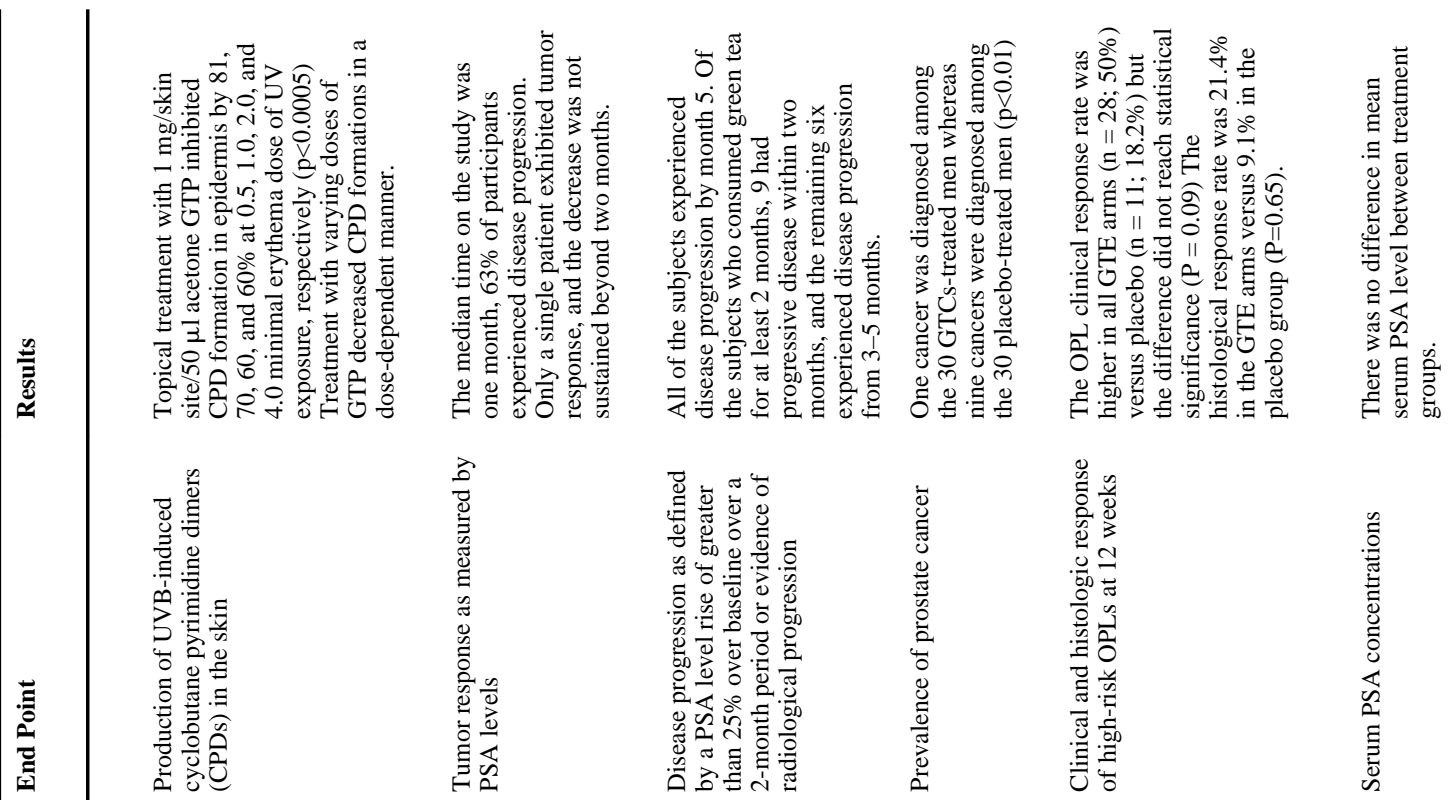

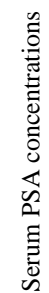

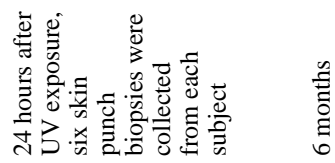
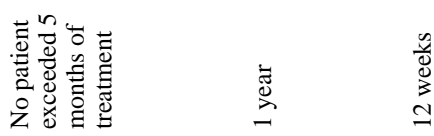

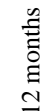

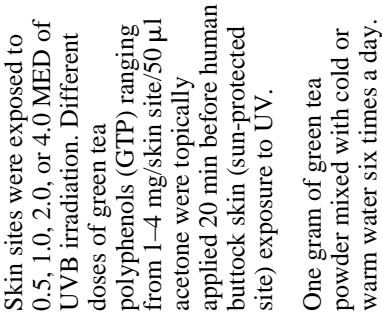
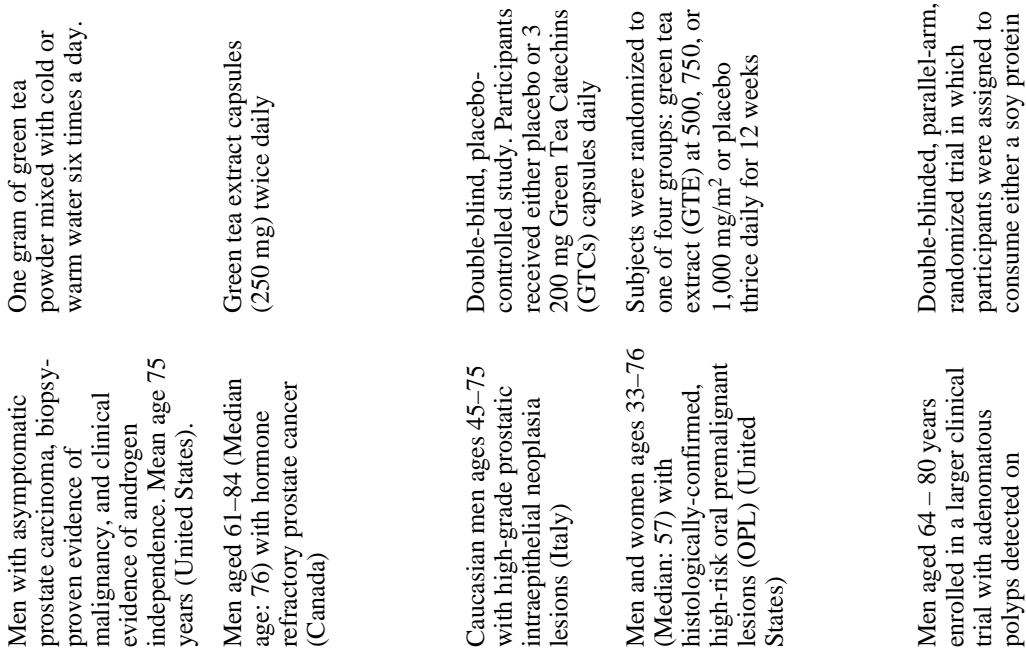

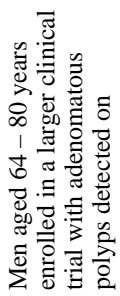

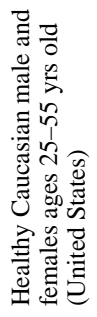

ร

2

8

ஏ

$\infty$

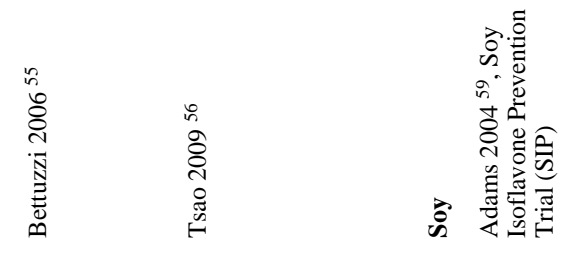




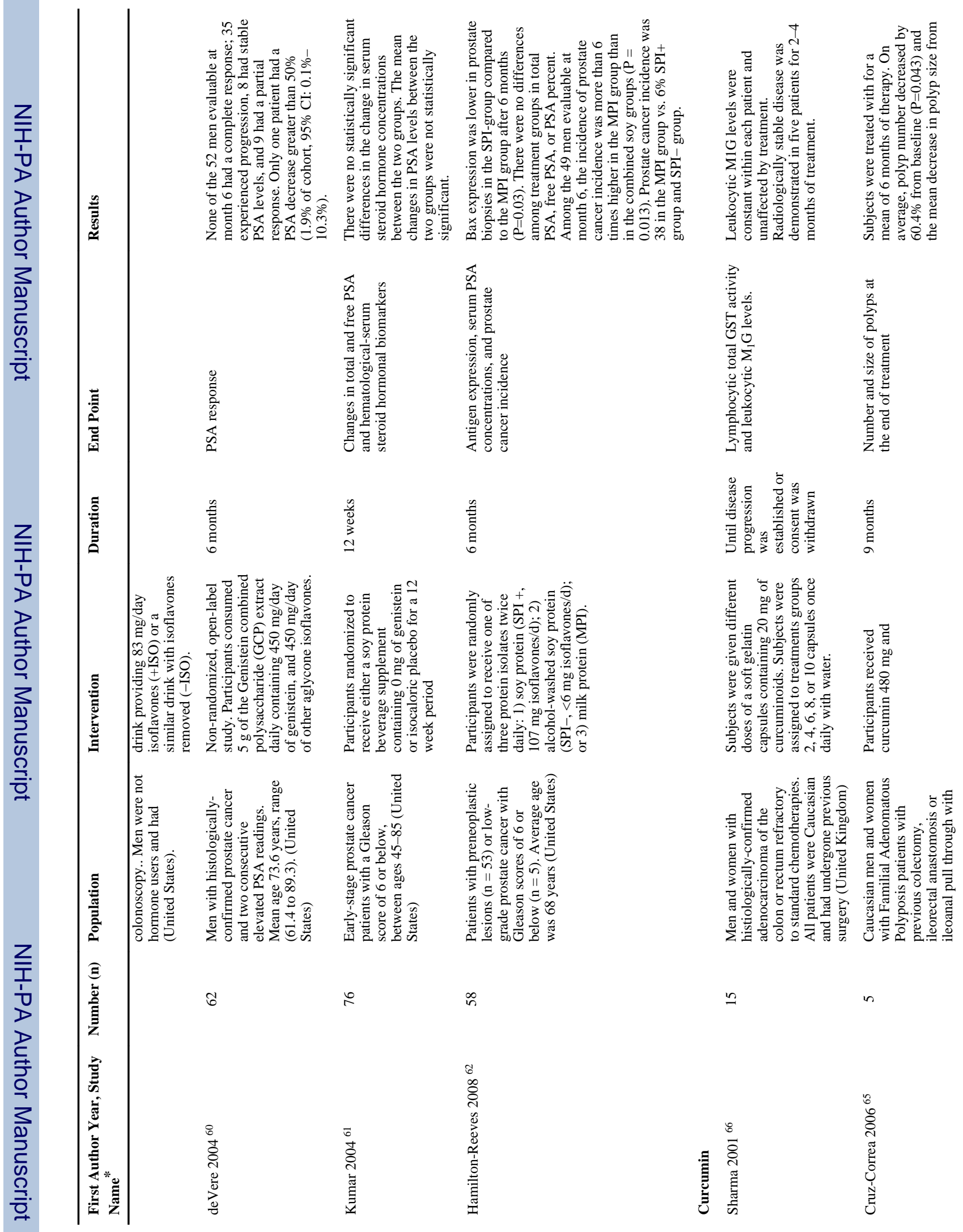




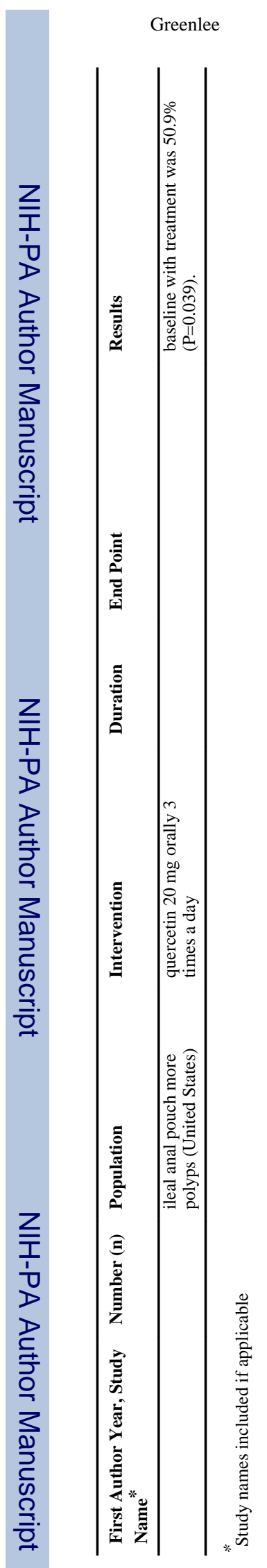

Page 20

Semin Oncol Nurs. Author manuscript; available in PMC 2013 August 21. 


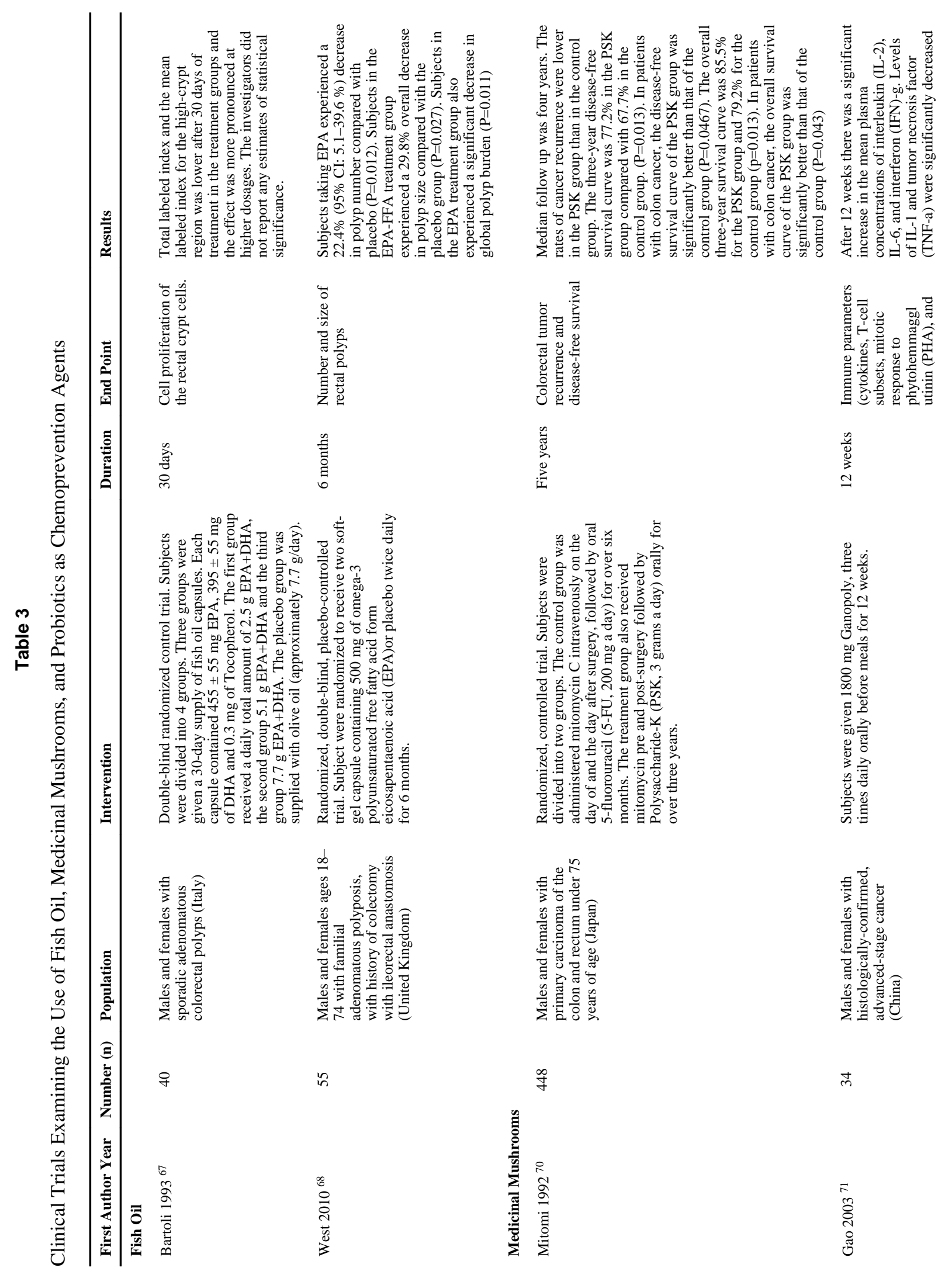

Semin Oncol Nurs. Author manuscript; available in PMC 2013 August 21. 


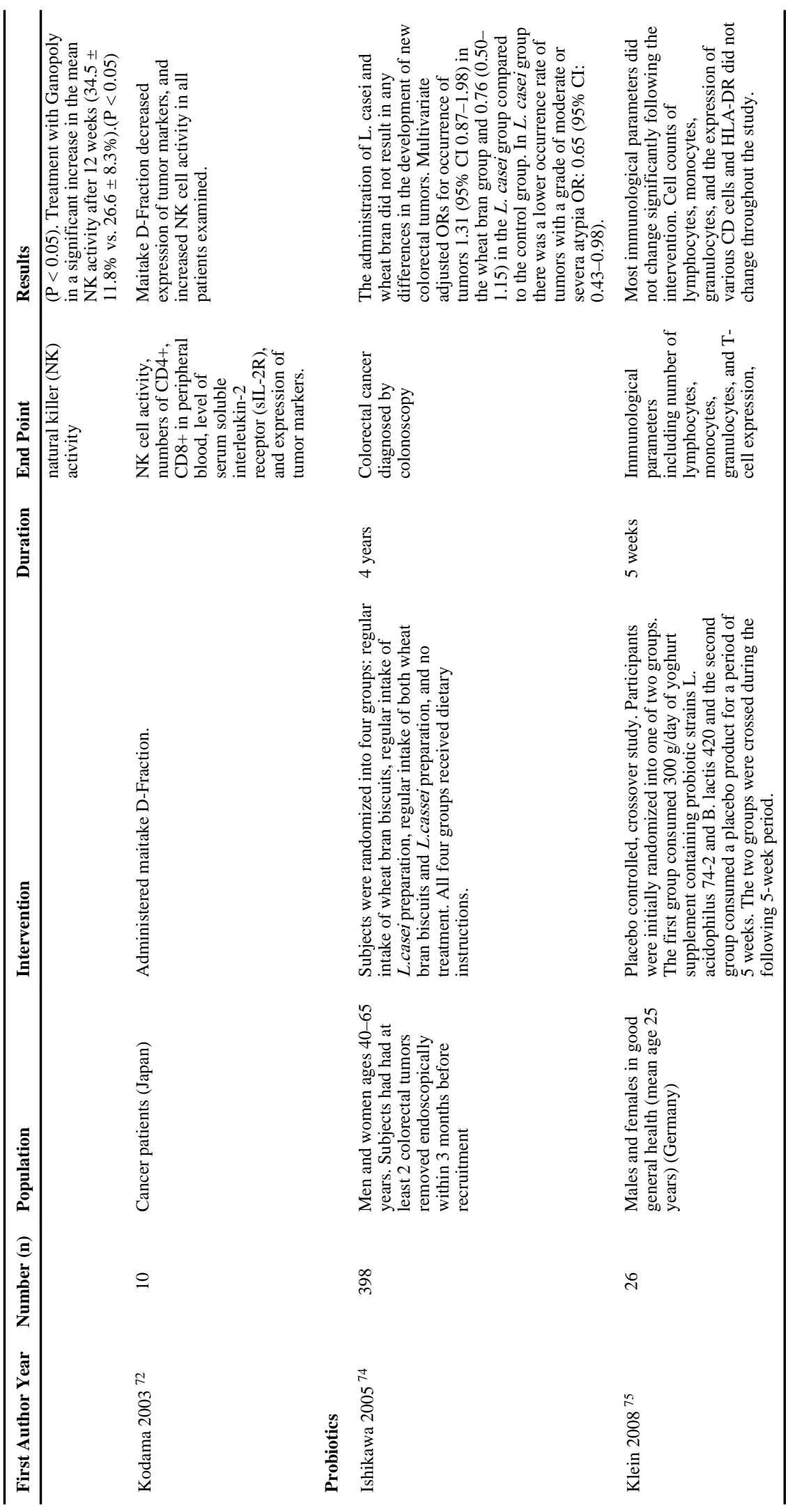


